\title{
NUMERICAL EVALUATION OF SLAB THICKNESS EFFECT ON THE IMPACT BEHAVIOR OF CONCRETE SLABS REINFORCED WITH CFRP BARS
}

\author{
${ }^{\star}$ Mohammed A. Dheyab
}

Mu'taz K. Medhlom

1) Civil Engineering Department, College of Engineering, Mustansiriyah University, Baghdad, Iraq

\begin{abstract}
Theoretical investigation of the nonlinear behavior of concrete slabs reinforced with CFRP bars subjected to a single impact load is presented in this paper. For predicting the impact load on a concrete slab, there are several methods, some of which are impractical or prohibitively pricey; however, due to significant technological advancements, simulation methods instead of experimental approaches have become common methods and a cost-effective matter for developing detailed responses. The purpose of this paper is to numerically investigate the effect of slab thickness on the impact response of concrete slabs reinforced with (CFRP) bars when subjected to a single impacting load, so as to well understand their behavior which are considered modern topics and rarely highlighted. Three specimens $(1800 \times 1800) \mathrm{mm}$, with three thicknesses 80,130 and 180 $\mathrm{mm}$, simply supported by their corners, have been modelled, one reference specimen of $130 \mathrm{~mm}$ thickness. The reference slab numerically validated with an experimental work from literature under dropping-weight of $150 \mathrm{~kg}$, it was a flat-nosed rigid steel $(300 * 300 * 700)$ $\mathrm{mm}$ projectile, used to apply impacting load, which is falling freely from a height of $3.26 \mathrm{~m}$. To assess slab behavior, impact force-time, displacement-time and reaction force-time histories had been plotted and discussed. The analytical results showed that slab thickness is a control factor and better performance in slabs reinforced with CFRP bars, can be achieved by increasing slab stiffness via its thickness increase.
\end{abstract}

Keywords: Impact load, CFRP bars, Abaqus, slab thickness.

\section{Introduction}

There is still a lack of knowledge about the dynamic behavior of reinforced concrete (RC) structures, where they are analyzed and designed currently on the basis of their static response [1]. Reinforced concrete structures may be subjected to a variety of dynamic loads during their service lives, including seismic, rocks' fall, blast loads and accidents can all cause impact loads. Military bombardment or unintentional explosions can result in blast loads. As a result of these types of dynamic loading, a structure's loading rate can change, causing the structure to respond dynamically in a different way than it did statically before. So, a structural member that fails under static load but fails in shear when the loading rate is increased, for example. It has also been found that reinforced concrete members can withstand higher loads as the loading rate increases. The main reasons for these differences are inertial effects, stress wave propagation, and strain rate effects on the constitutive properties of reinforcement and concrete [2]. Depending on Bischoff and Perry [3], induced and blast loadings generate high strain rates $(10 \%$ to $\left.10^{3} / \mathrm{s}\right)$.

Figure 1 illustrates that static load result in low rates of strain $\left(10^{-6}\right.$ to $\left.10^{-4}\right)$ while earthquakes produce medium rates of strain $\left(10^{-3}\right.$ to $\left.10^{0}\right)$ and impact or blast loads produce high strain rates

*Corresponding Author: mhmddnan@gmail.com 
$\left(10^{0}\right.$ to $\left.10^{3}\right)$. As a general rule, inertial force plays a significant role in impact and explosive problems, while strain rate has a significant effect on concrete and steel's constitutive properties when the strain rate exceeds $\left(10^{\circ} / \mathrm{s}\right)$. Figure 1 depicts limitations of strain rate.

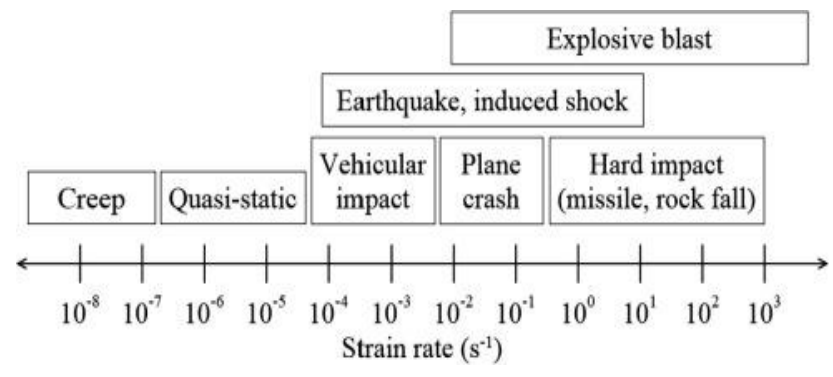

Figure 1. Variations in strain rates due to different loading conditions [4]

The poverty of data from high-velocity loading tests limits future comprehension of the effect of rate of loading on slab response. Due to this, it is urgent that RC slabs be subjected to high-quality fast loading tests In addition, impact loading cannot be viewed as a simple extreme case of rapid loading because is characterized by a large amount of inertia, energy and propagation of stress waves mechanisms [4]. According to the stiffness of the impactor, the impact problem can be classified as hard or soft impact. In a hard impact, the impactor's stiffness is extremely high, and the impactor's deformation during impact is minimal. As a result, the impactor's deformation can only dissipate a small portion of the impact energy. During soft impact, from the other hand, the impactor's stiffness is fairly low, and its deformation during the impact process must be considered. Due to the impactor's deformation, some of the impact energy can be dissipated. As a result, most impact research focuses on hardimpact issues. Experimental studies have been carried out by researchers with the goal of revealing failure mechanisms of RC structures under impacts. Reinforcing concrete members with fiber reinforced polymer (FRP) materials is a new technique that is appealing due to its benefits in increasing flexural and shear capacities. What follows is a summary of the findings of some studies: Nguyen-Minh and Rovnak [5] studied the punching shear behavior of six large-scale interior glass fiber reinforced polymer (GFRP) and steel-reinforced slabcolumn connections, with slabs measuring $220 \mathrm{x}$ $220 \times 15 \mathrm{~cm}$ and columns measuring $20 \times 20 \mathrm{~cm}$. Specimens were divided into two groups, with three reinforced with G.F.R.P bars and three reinforced with conventional steel bars. Flexural reinforcement ratios ranged from 0.4 to 0.8 , with no compression reinforcement used in any of the slabs. All slabs were simply supported on all four sides and subjected to a concentrated load acting on the column stub in the center of each slab. According to the study, increasing the G.F.R.P reinforcement ratio increased punching shear strengths by up to $36 \%$ while decreasing deflection by nearly $35 \%$. El-Ghandour et al. [6] studied the punching shear behavior of 2-way G.F.R.P reinforced slabs with and without G.F.R.P shear reinforcement. The researchers tested eight 200x200 cm square simply supported specimens in a two-phase experimental program. All specimens were $17.5 \mathrm{~cm}$ thick, with a column 20x20 cm square. All specimens were tested with a concentrated load at the slab's center. The first phase included the testing of four specimens. Two slabs were reinforced with G.F.R.P bars $(\rho$ $=0.18 \%)$ and two with C.F.R.P bars $(\rho=0.15 \%)$. The flexural reinforcement ratio was increased to $0.38 \%$ in the second phase. The specimens failed due to bond slip of the flexural bars at loads less than their expected flexural and punching shear capacities in the first phase due to their relatively low reinforcement ratio and wide spacing between the reinforcement bars. Flat slabs reinforced with C.F.R.P sheets located on the slab's tension side were tested by Esfahani et al. [7]. Additionally, they found that using C.F.R.P sheets as flexural reinforcement in addition to 
steel reinforcement bars increased the slabs' punching shear strength.

\section{Numerical Analysis}

The numerical analysis mainly involves two parts, material properties and validation process. Understanding of material properties in high strain rates' cases is a most significant concept that needs deep observation, particularly when related to a proper definition of its behavior. The individual behavior of concrete and reinforcement in relation to strain and loading rates will be discussed in this section. The significant issues in this section are identified by an explanation of some fundamental concepts regarding modelling the behavior of material. The first concept is the behavior of concrete in compression and tension and the second is modelling the constitutive models of the model's parts. However, an accurate and sound understanding of modelling can help bridge the gap between research and practice. As a result, simulating the cracking and post-cracking behavior of concrete, which is undoubtedly the most crucial non-linear analysis, depends on obtaining reliable data.

\subsection{Behavior of Concrete in Compression}

Depending on Canadian Standard CSA A23.314 , the stress-strain curve exhibits assumed linear response up to a stress level of around $0.4 \mathrm{fc}^{\prime}$. A level of $0.4 \mathrm{fc}^{\prime}$ causes concrete to develop microcracks and the response becomes highly non-linear. On the compression stress-strain curve for concrete, the curve initially rises until it reaches a peak equal to the maximum compressive stress, then descends until it reaches the ultimate strain level, which is assumed to be around $35 \times 10^{-4}$ on the curve, many analytical models have been enveloped. According to Warner et al. (1998) the strength of the concrete can be considered by comparing it to a different slope refer to Figure 2 [8].

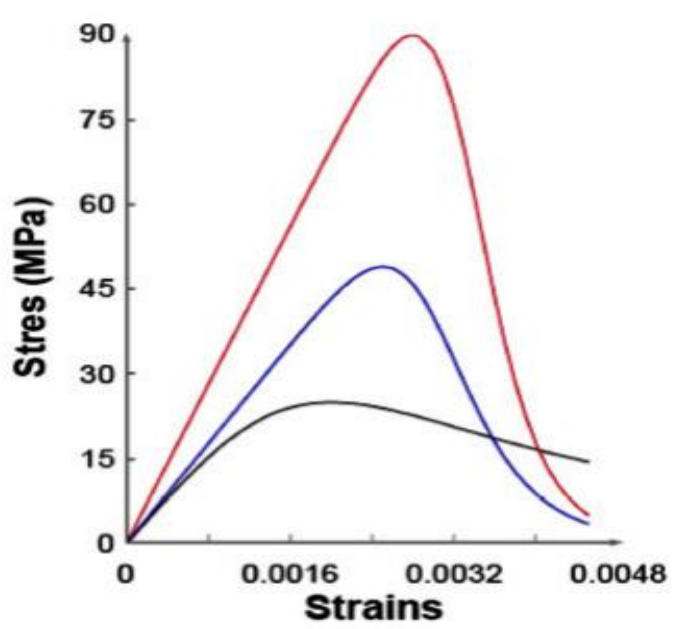

Figure 2. Stress-strain curves of different type of concrete [9]

\subsection{Behavior of Concrete in Tension}

Tension Softening: When concrete is loaded in compression, it exhibits an elastic response at first. As the stress rises, inelastic straining occurs, which is irreversible, and the material response softens. When a material softens, it reaches an ultimate stress beyond which it can no longer carry any stress. If the load is removed after inelastic straining has occurred, the unloading response is softer than the initial elastic response, indicating that the elasticity has been damaged. Tensile stresses cannot be transmitted through cracks in concrete, however, because of the bond between the concrete matrix and the aggregate friction interlock, concrete between cracks can withstand tensile forces. With an increase in tensile force, more cracks appear, and less concrete is available to support the tension as a result. This implies that the concrete will continue to sag until it reaches $\mathrm{ft}^{\prime}$, the maximum tension. Most people agree that the value of $\mathrm{ft}^{\prime}$ is $0.33 \%$ of the value of $\mathrm{fc}^{\prime}$. When tensile stress exceeds $\mathrm{ft}^{\prime}$, the cracking damage becomes so severe that any increase in deformation reduces the concrete's ability to transfer stress. Tension softening is the term for a decrease in tensile capacity. Thereafter, the 
stress-strain curve descends until it reaches a tensile strain of $\varepsilon \mathrm{u}$, at which point there is no more residual tensile strength left [9].

Tension Stiffening: The presence of reinforcement stiffens and engages the concrete between the cracks through local bond stress transfer associated with local bond-slip.

This behavior improves the softening response by introducing the tension stiffening effect, which causes the average tension concrete stress to gradually decrease to zero as cracking intensifies. Tension stiffening and local bond slip are two separate but related phenomena with opposing effects.

As a result, it is extremely difficult to separate the two. As a result, the so-called tension stiffening models account for the effect of both at the same time.

An axial force-average strain plot of reinforced concrete specimens is shown in Figure 3, superimposed on a graph of bare steel bars. Bare bar response is a simulation of what would happen when only the steel bar is able to resist tension forces while the concrete surrounding it is ignored.

This occurs when axial tension just under N2 in Figure 3 causes crack in the concrete, reducing tension and reducing deformation response to that of a bare rod [10].

As shown in Figure 3, the maximum load is limited by the yield strength of the bar.

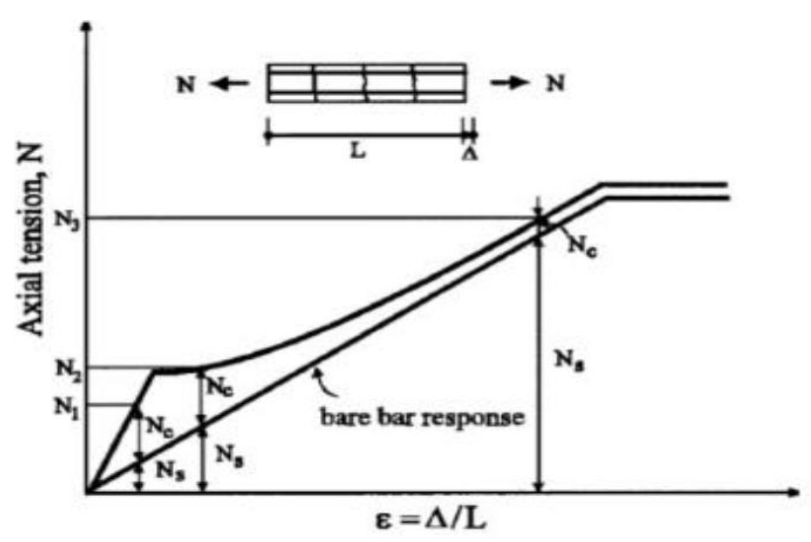

Figure 3. Tension stiffening and softening curves for reinforced concrete

\section{Element Type}

In ABAQUS, the concrete block can be modelled as $2 \mathrm{D}$ or $3 \mathrm{D}$ solid or shell element as shown in Figure 4, for complicated problem such as impact response $3 \mathrm{D}$ element is found to be more accurate in representing the three-dimensional stresses. Reinforcing bars can be modelled by either a discrete or embedded element as shown in Figure 5. With the discrete element, which can take solid beam element, It's assumed that the bond between the reinforcing bar and the concrete is perfect unless idealized linkage elements having a spring stiffness with a defined bond-slip relationship are used. The drawback of the discrete approach is that the mesh discretization is restricted at the location of the reinforcement which could be complicated in some cases. With the embedded option available in ABAQUS this problem is overcome by allowing the compatibility in the displacement between the concrete and the reinforcement in any layout without any complication in the meshing process. The embedded method is advantageous in simulating most of RC structures which have reinforcement with complex layout scheme.

In this study, 3D hexahedron brick element with eight nodes (C3D8R) was selected to model the concrete block and support plates. As described in the ABAQUS/Explicit user's manual, the 
eight-node continuum elements (C3D8R) are described as Lagrangian elements that deform with material deformation. The displacements at each node are calculated at the same time, and linear interpolation can be used to calculate displacements at any other point within the element.

An embedded 3D truss element with two nodes (T3D2) was selected to model the steel and CFRP bars assuming perfect bond between the reinforcing bars and the concrete. Figure 4 and Figure 5 show the FE models used for the concrete and the reinforcing bars of the slab, respectively.

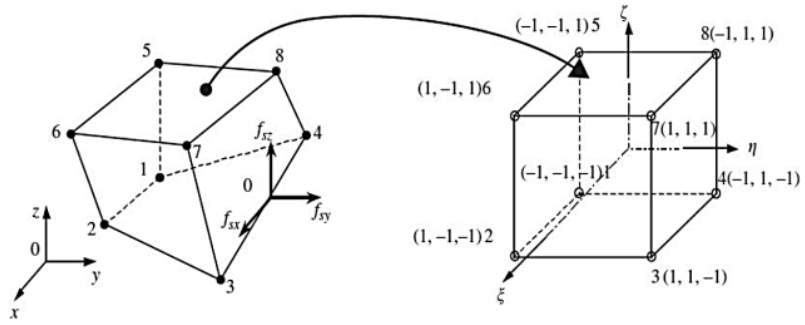

Figure 4. Eight node hexahedron brick element [12]

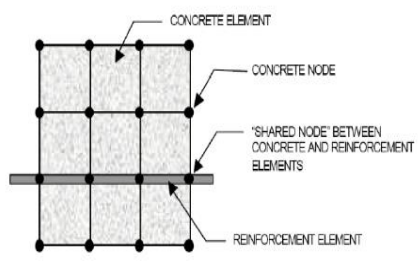

(a) Discrete model

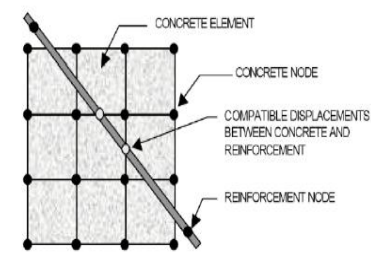

(b) Embedded model
Figure 5. Representation of reinforcement in concrete model [12]

\section{Material Constitutive Modelling}

Since the stress-strain relationship of the constitutive material plays an important role in the structural response of the member to the applied load, defining this relationship is crucial in any numerical analysis approach. ABAQUS has many models to define different types of materials having different physical state and mechanical properties. Commercial software used to simulate concrete structures subjected to impact loads uses a variety of material models to represent concrete. When it comes to concrete modeling in ABAQUS, the most commonly used models include the Concrete Damage Plasticity (CDP) model, the Concrete Smeared Crack Model, and the Modified Drucker-Prager/Cap Model. In the present study "Concrete Damage Plasticity" model has been employed to model concrete material of RC structure.

\subsection{Concrete Damage Plasticity (CDP)}

In ABAQUS, the concrete damaged plasticity (CDP) model allows for the general modeling of concrete and other quasi-brittle (rock, brick, etc.) materials in all kinds of structures (beams, trusses, shells, and solids).

The CDP model incorporates concepts of isotropic damaged elasticity, as well as isotropic tensile and compressive plasticity, to represent the inelastic behavior of concrete. Although it is designed primarily for RC structure analysis, it can also be used for plain concrete. It is intended for use in applications where concrete will be subjected to monotonic, cyclic, and/or dynamic loading.

The concrete damage model is a continuum, plasticity-based model. Tensile cracking and compressive crushing of the concrete material are assumed to be the main two failure mechanisms.

Two hardening variables, $\tilde{\varepsilon}_{\mathrm{t}}^{\mathrm{pl}}$ and ${\tilde{\varepsilon_{\mathrm{c}}}}_{\mathrm{pl}}^{\mathrm{pl}}$ tensile and compressive equivalent plastic strains, inked to failure mechanisms under tension and compression loading, respectively, control the evolution of the yield (or failure) surface.

A damaged plasticity is assumed to characterize the uniaxial tensile and compressive response of concrete, as shown in Figure 6. 

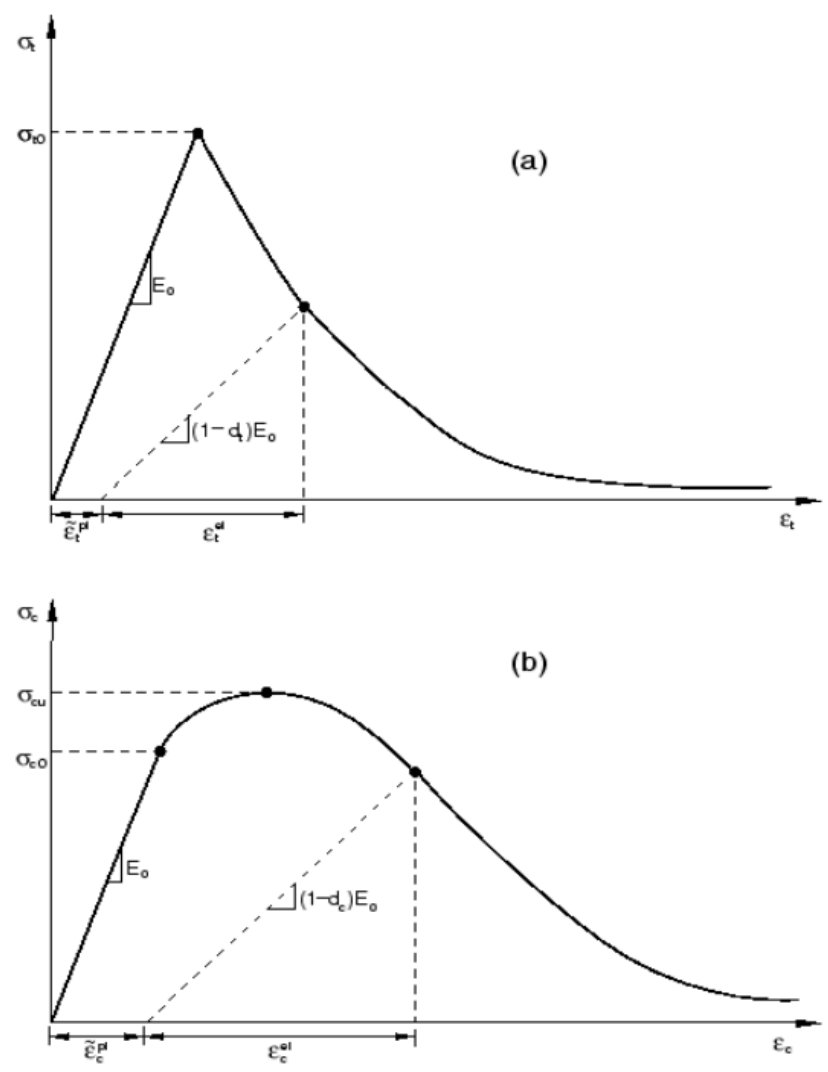

Figure 6. Tensile and compression responses of concrete to uniaxial loading (a) tension and (b) compression [13]

Failure criteria for concrete in tension and compression was developed by Kupfer (1973) [11] with five parameters have been used in FE analysis of RC member. These parameters are listed in Table 1 below.

Table 1. Parameters used for failure criteria

\begin{tabular}{cc}
\hline Parameter & Denotation \\
\hline$\Psi^{*}=38 \mathrm{o}$ & Dilation angle \\
$\mathrm{fb} 0 / \mathrm{fc} 0=1.16$ & Ratio of biaxial to \\
& uniaxial compressive \\
& strength \\
$\mathrm{K}=0.67$ & Second stress invariant \\
& ratio \\
$\mathrm{e}=0.1$ & Eccentricity \\
$\mu=0$ & Viscosity parameter \\
\hline
\end{tabular}

\subsection{Constitutive Model of CFRP Rebars}

To establish an accurate model to simulate the actual behavior of CFRP, a direct tensile test was needed to be conducted on CFRP bar to obtain the mechanical properties of the CFRP bars used in this research. Based on the obtained results by the manufacturer, a linear stress-strain relationship up to the ultimate failure stress was assumed as showed in Figure 7.

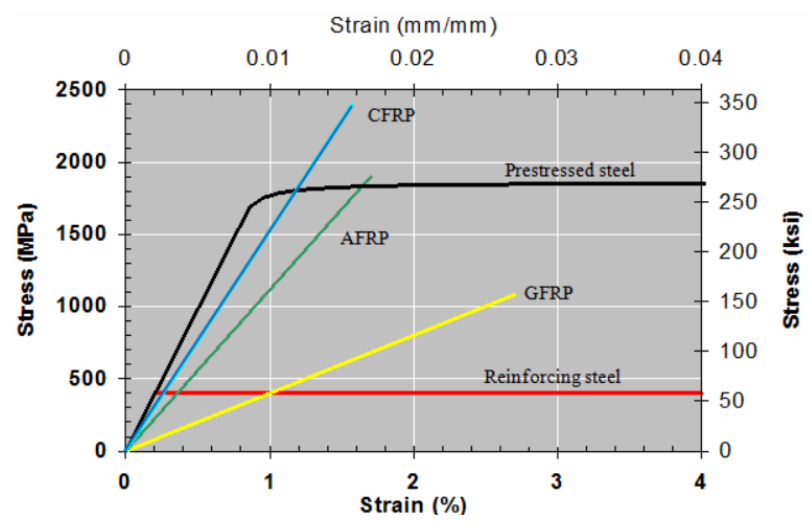

Figure 7. Stress-strain curves of FRP bars [15]

In this study, since the implemented CFRP technique uses the composite as a onedimensional reinforcing bar and the geometry is modeled by using truss element [12], based on that, a linear elastic stress-strain model was selected to model the CFRP material by defining its modulus of elasticity and Poisson's ratio. Brittle failure model was used to model the failure by defining the fracture strain of CFRP which was taken as 0.0175 as obtained from the properties of bar of diameter $10 \mathrm{~mm}$.

\section{Mesh Process}

A model's meshing capabilities are divided into three categories in ABAQUS: the function for mesh attribution, the function for mesh generation, and the function for resizing the mesh, and the function for mesh verification. There are also a number of techniques to subdivide any type of elements into tiny mesh elements; however, the free meshing technique is the most flexible. The first step is to determine the number of seeds per edge, and by using this option the feasibility of distributing seeds 
uniformly along an edge can be seen. Moreover, because the struck area is notable, it should be attributed to fine meshing as much as possible, rather than the other regions if the overall fine meshing may delay the solution time. For instance, Figure 8 presents the quality and quantity of seeds per edge in the concrete slab with same mesh size for all parts of the model.

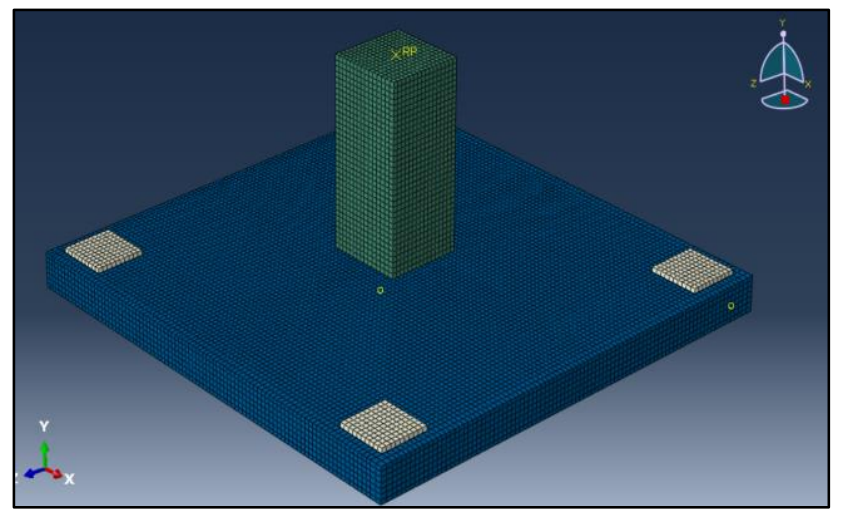

Figure 8. A sample of meshing

Selecting the appropriate element for mesh generation is another important topic covered in this section. The ABAQUS/Explicit library contains a variety of element types that can be used to fulfill a specific request. Thus, the 3D stress element type was chosen to define the individual points of this numerical calculation, in conjunction with the reduced integration. A brief explanation of the Hourglass Control and distortion Mesh Control Techniques will also be provided. The use of a reduced-integration scheme can cause the mesh to become unstable. This is commonly referred to as "hour glassing". Generally, both Hourglass and control of mesh distortion can enhance global strain, stiffness, viscous, and a combination of stiffness and viscous. But when it comes to using very fine mesh, controlling distortion may play a significant role in a realistic simulation. Another important aspect of creating mesh in the Master and Slave surfaces is the impactor mass. Because there should never be more seeds on the Master surface than on the slave surface, this is correct.
The slave surface should have the same number of seeds as the master surface, or at least have more seeds per unit, so that elements in the master surface can absorb discrete elements in the slave surface. Finally, Table 2 below shows the types and numbers of nodes and elements for the different parts

Table 2. Mesh details by ABAQUS

\begin{tabular}{cccc}
\hline Part & Element type & $\begin{array}{c}\text { No. of } \\
\text { elements }\end{array}$ & $\begin{array}{c}\text { No. of } \\
\text { nodes }\end{array}$ \\
\hline Slab & $\begin{array}{c}\text { Linear hexahedral } \\
\text { C3D8R }\end{array}$ & 57330 & 66976 \\
CFRP & Linear line T3D2 & 4420 & 4420 \\
$\begin{array}{c}\text { bars } \\
\text { plates }\end{array}$ & $\begin{array}{c}\text { Linear hexahedral } \\
\text { C3D8R }\end{array}$ & 800 & 1936 \\
Impactor & $\begin{array}{c}\text { Linear quadrilateral } \\
\text { R3D4 }\end{array}$ & 2768 & 2763 \\
\hline
\end{tabular}

\section{Validation}

This part presents the results of the validation process with the experimental results done by Trevor D.Hrynyk and Frank J. Vecchio [13] with respect to $\mathrm{RC}$ slab, regarding to slab reinforced by CFRP bars.

The adopted results for the validation process are the summation of supports' reaction force-time history and maximum mid-point displacementtime history at the impact moment which are considered the critical values.

It is clear from the Figure 9 and Figure 10 shown below that ABAQUS accuracy exceeded 90\% regarding to reaction force which was 578.056 $\mathrm{kN}$ with comparison with the practical results $556 \mathrm{kN}$ according to the provided graph [13] [14]. 


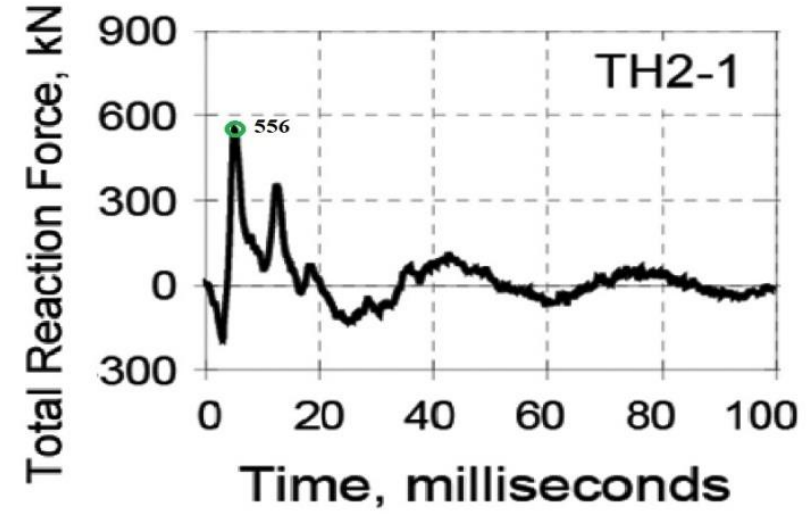

Figure 9. Practical results of supports' reaction force [17]

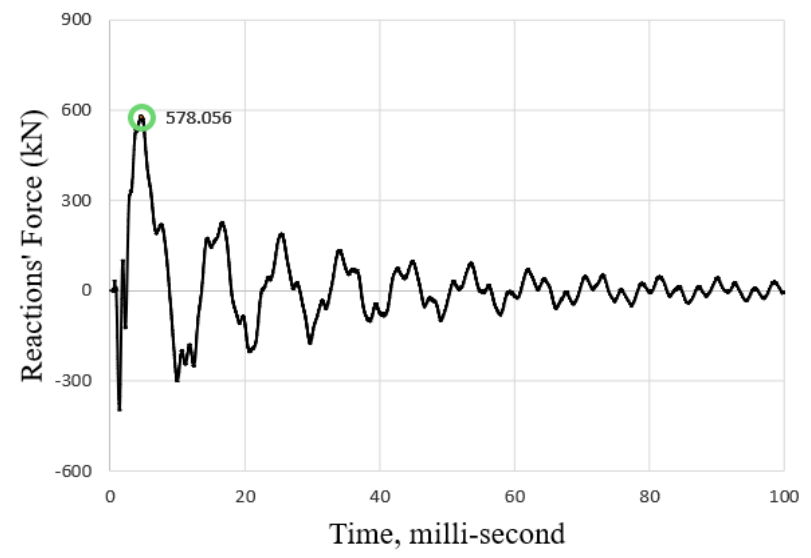

Figure 10. Numerical results of supports' reaction force by ABAQUS

The reaction forces from the four corner supports were combined to evaluate the overall slab reaction force-time history.

The analytical results underestimated the inertial resistance force which resulting in overestimating the experimental reaction force just by $3.7 \%$, this high agreement percentage consider a very good motivation to adopt all the next analyses results.

Figure 11 compares the experimental displacement histories with the numerical ones.

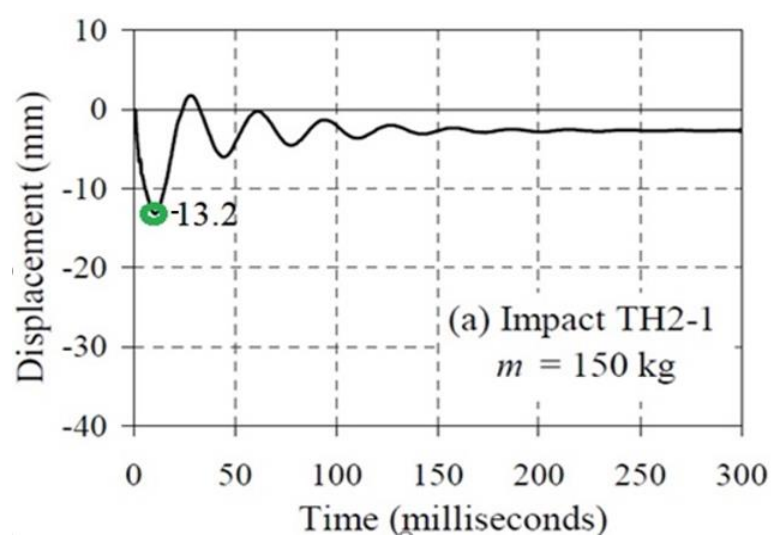

(a) Experimental

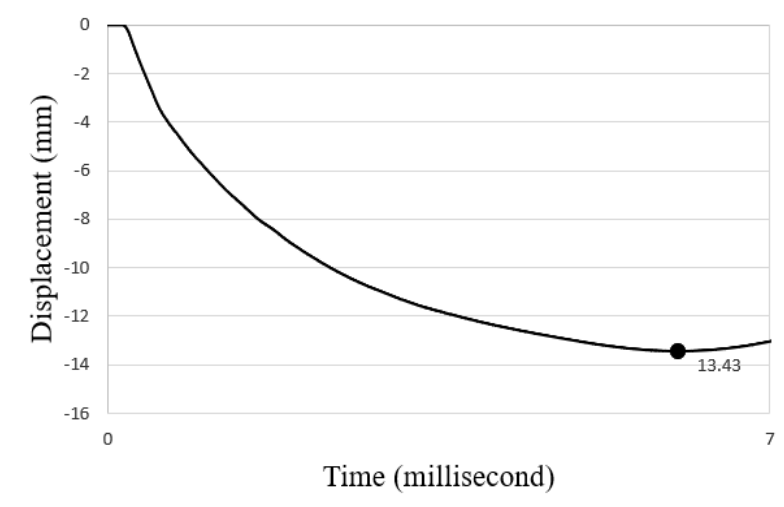

(b) Numerical by ABAQUS

Figure 11. Validation displacement-time histories comparison

It is evident that ABAQUS accuracy regarding to the peak mid-point displacement value exceeded $90 \%$ which was $13.43 \mathrm{~mm}$ with comparison with the experimental results which was $13.2 \mathrm{~mm}$ according to the provided graph [13].

\section{Parametric study}

Three slabs reinforced by CFRP bars and having different thicknesses had been modelled to examine their response under the effect of the impact load. The first reference slab is denoted by (R-1), the other two slabs were denoted by ( $\mathrm{T}$ 180) and (T-80) having thicknesses of 180 and 80 $\mathrm{mm}$, respectively. Other properties are listed in Table 3. 
Table 3. Properties of the slabs with different thickness

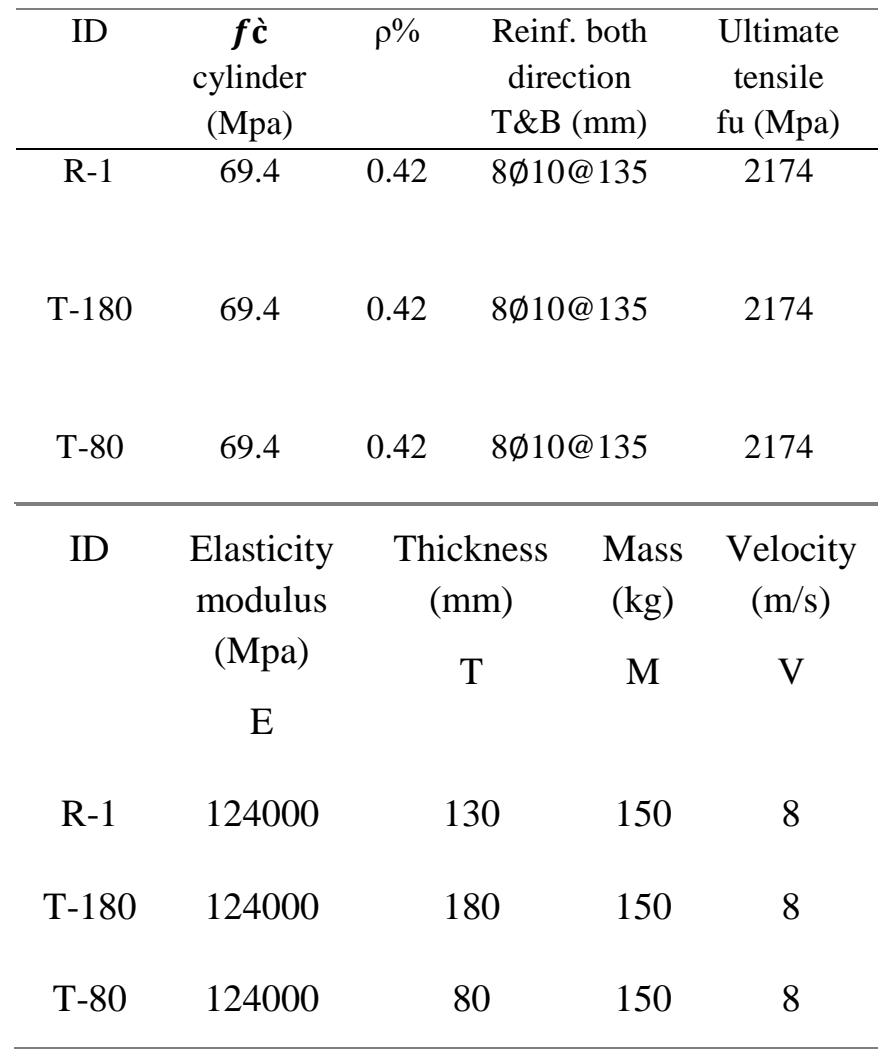

Figure 12 shown below refers to the assembled model including all the modeled parts.

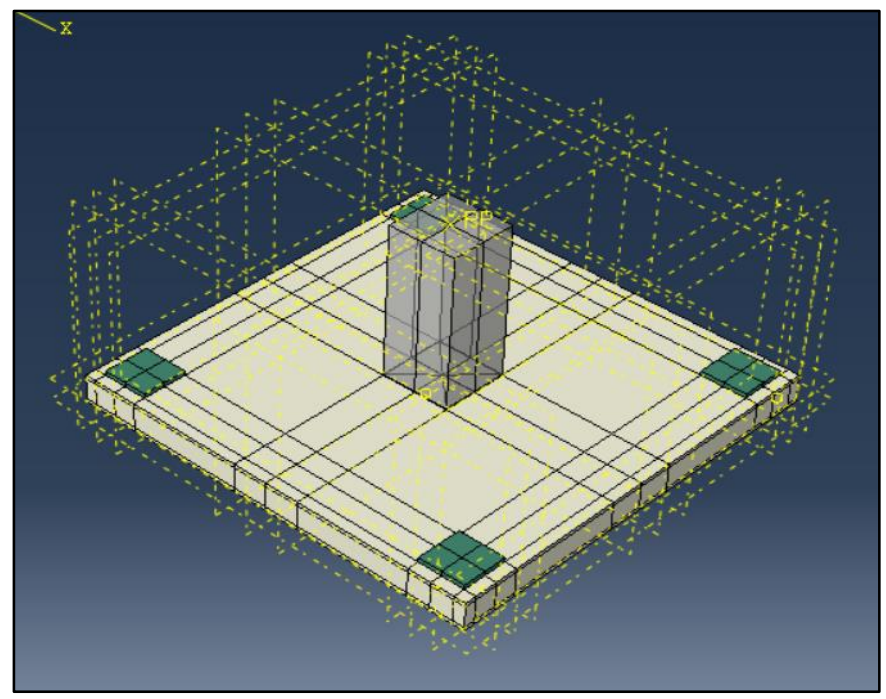

Figure 12. Top view of assembly of the model after creating instances

\section{Results and Discussion}

Peak results of this parametric case with comparison to the reference case $(\mathrm{R}-1)$ shown in the following graphs.

\subsection{Reaction Force}

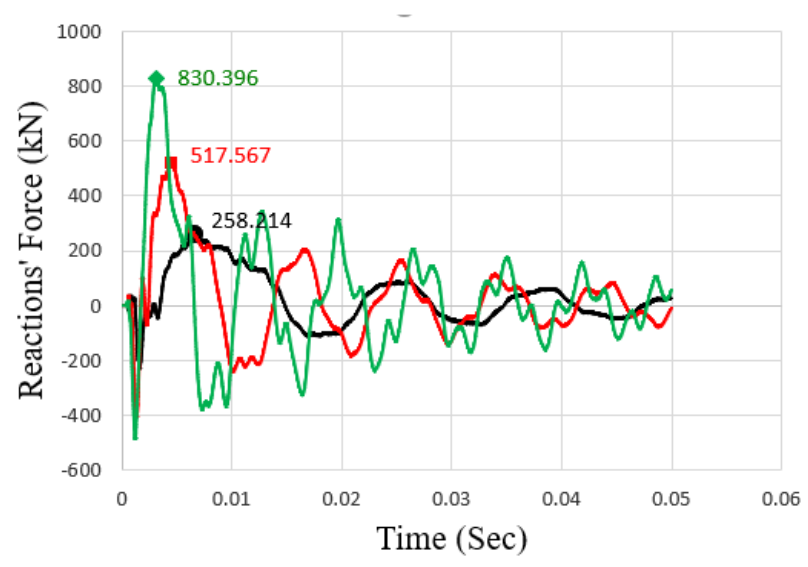

Figure 13. Reaction force histories for different slab thickness

Reaction force increased $60.5 \%$ by increasing slab thickness $38.46 \%$ that is due to the high impact force with the low duration which permits to load to turn toward the supports. And vice versa, reaction force decreased $50.1 \%$ as the thickness decreased $38.46 \%$, which permits the higher impulse affects effectively on the slab for a longer time (further distribution) which allow to little amount of load to be resisted by the supports.

\subsection{Impact Force}

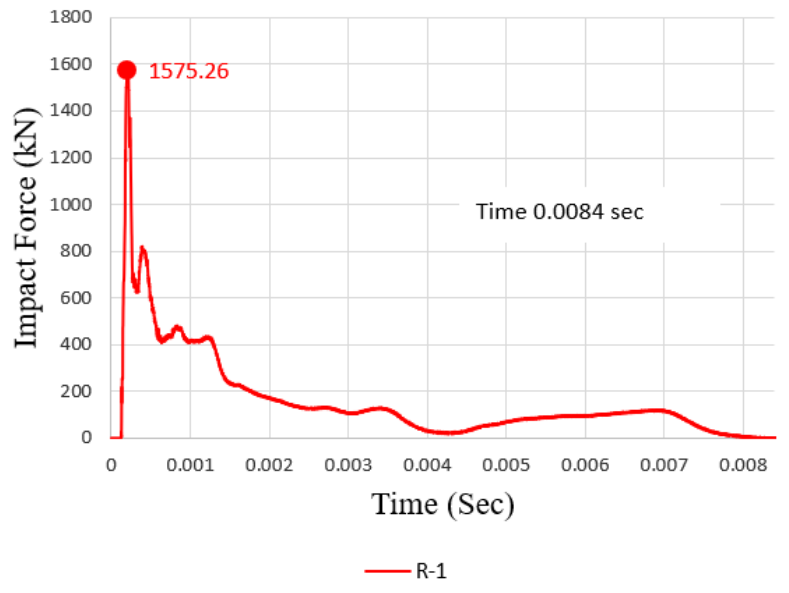



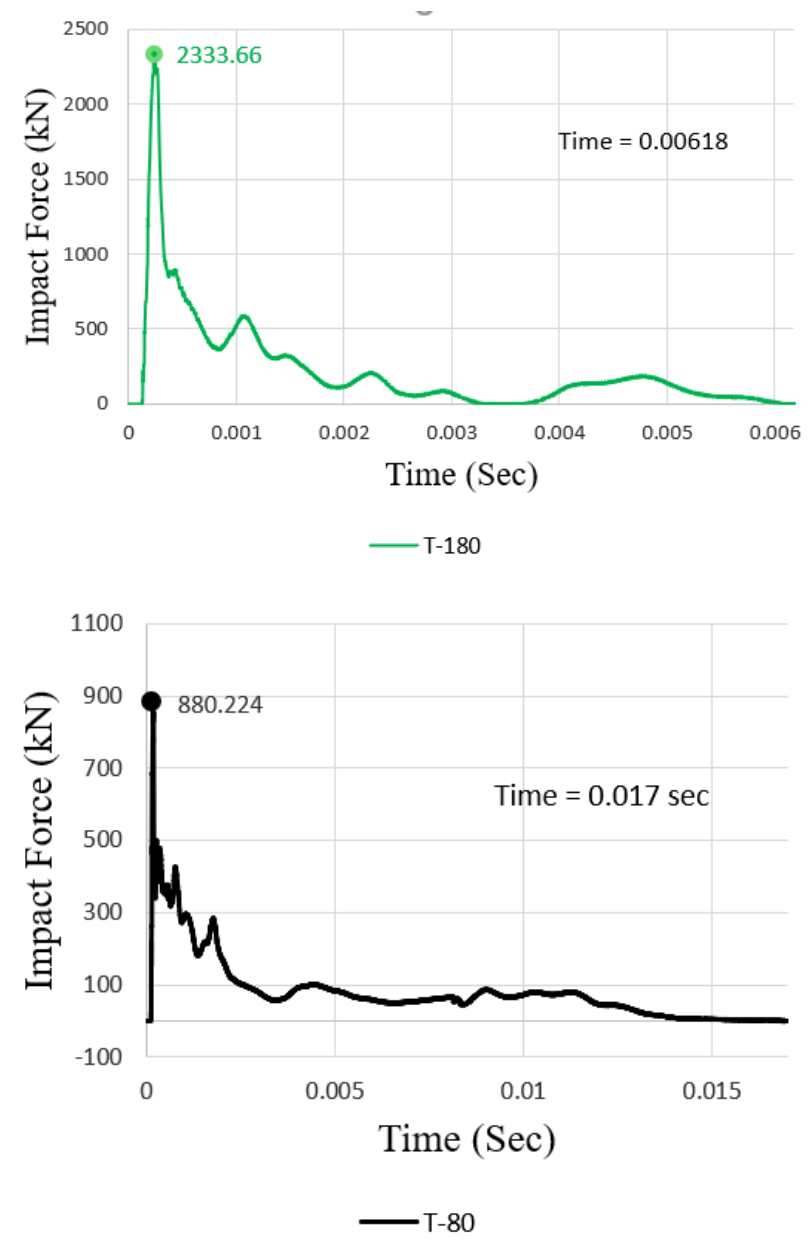

Figure 14. Impact force histories for different slab thickness

It is shown that the increasing slab of thickness $38.46 \%$ in order to make it $180 \mathrm{~mm}$, Impact force increased $48.1 \%$ with a shorter duration than R1. The additional stiffness resulting from the increase in thickness, which in turn increases the absorption of the energy exerted on it and lower impulse with lower effect duration.

While, the decreasing slab thickness $38.46 \%$ in order to make it $80 \mathrm{~mm}$. Impact force decreased $44.1 \%$ but taking a longer effect duration than $\mathrm{R}$ 1 and T-180. Also, increases the impulse effect as a result of the weakness that occurred in the slab, due to reducing its thickness to nearly half which allowed for lower energy absorption.

7.3. Displacement

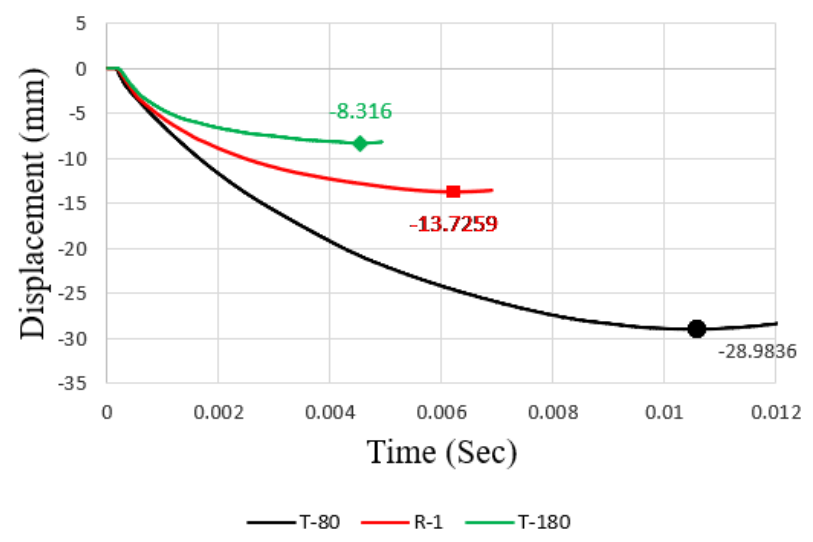

Figure 15. Displacement histories for different slab thickness

Displacement decreased $39.4 \%$, by increasing slab thickness $38.46 \%$ that is due to the inertial strengthening gained by the larger thickness, which is inversely proportional to the displacement according to the minimum slab thickness determined by ACI and other codes. While, displacement increased $111.2 \%$ as the thickness decreased $38.46 \%$, it is evident that slab thickness decreasing leads to lack of slab efficiency, which, in turn, dominated the role of the reinforcement in keeping the displacement of more increasing.

\section{Conclusion}

Based on the findings of the current study, the following conclusions can be drawn:

1. The numerical analysis using ABAQUS on the impacted concrete slabs reinforced with CFRP bars is validated.

2. The impact behavior of concrete slabs reinforced with CFRP bars is dependent on the slab thickness, which plays a key role in the slab resistance, stiffness and inertial force development.

3. Slabs with greater thickness showed better resistance than the others. 
4. The peak impact force increases directly with the increase of slab thickness with a lower effect duration due to the greater stiffness resulting in increasing the inertial role.

5. The mid-point displacement profiles for the higher thickness showed less values and faster rebounding than the others.

6. Reaction forces by the slab of a higher thickness were took their roles faster and stronger than the others.

7. The slabs under single impact, particularly under flat-nosed impactor didn't appear a local failure at least for these thicknesses.

\section{Abbreviations}

$\mathrm{FRP}=\quad$ Fiber reinforced polymer

$\mathrm{CFRP}=$ Carbon fiber reinforced polymer

$\mathrm{GFRP}=$ Glass fiber reinforced polymer

$\mathrm{ACI}=\quad$ American concrete institute

\section{Conflict of Interest}

The authors confirm that the publication of this article causes no conflict of interest.

\section{References}

1. Patterson and T. De Kerf, 1978, "Dynamic Behaviour of Extruders.," pp. 483-487.

2. S. Das Adhikary, B. Li, and K. Fujikake, 2015, "Parametric study of RC beams under a wide range of loading rates," Proc. Inst. Civ. Eng. Struct. Build.

3. P. H. Bischoff and S. H. Perry, 1991, "Compressive behavior of concrete at high strain rates," Mater. Struct., vol. 24, no. 6, pp. $425-450$.
4. R. J. Thomas and A. D. Sorensen, 2017, "Review of strain rate effects for UHPC in tension," Constr. Build. Mater. vol. 153, pp. 846-856.

5. S. Das Adhikary, "Dynamic behavior of reinforced concrete beams under varying rates of concentrated and impact loadings." $\mathrm{PhD}$ thesis, School of Civil and Environmental Engineering, Nanyang ..., 2013.

6. L. Nguyen-Minh and M. Rovňák, 2013, "Punching shear resistance of interior GFRP reinforced slab-column connections," J. Compos. Constr., vol. 17, no. 1, pp. 2-13.

7. A. W. El-Ghandour, K. Pilakoutas, and P. Waldron, 2003, "Punching shear behavior of fiber reinforced polymers reinforced concrete flat slabs: experimental study," J. Compos. Constr., vol. 7, no. 3, pp. 258265.

8. M. R. Esfahani, M. R. Kianoush, and A. R. Moradi, 2009, "Punching shear strength of interior slab-column connections strengthened with carbon fiber reinforced polymer sheets," Eng. Struct., vol. 31, no. 7, pp. 1535-1542.

9. A. Al Nussairi, 2018, "Characterising the static and impact load resistance of oneway RC slabs strengthened by NSM CFRP rods." University of Bristol.

10. A. Hillerborg, M. Modéer, and P.-E. Petersson, 1976, “Analysis of crack formation and crack growth in concrete by means of fracture mechanics and finite elements," Cem. Concr. Res., vol. 6, no. 6, pp. 773-781.

11. R. Nayal and H. A. Rasheed, 2006 , "Tension stiffening model for concrete beams reinforced with steel and FRP bars," J. Mater. Civ. Eng., vol. 18, no. 6, pp. 831841. 
12. A. J. Sangi, 2011, "Reinforced concrete structures under impact loads." HeriotWatt University.

13. M. Bypour, M. Gholhaki, M. Kioumarsi, and B. Kioumarsi, 2019, "Nonlinear analysis to investigate effect of connection type on behavior of steel plate shear wall in RC frame," Eng. Struct., vol. 179, no. January, pp. 611-624.

14. V. Birtel and P. Mark, 2006, "Parameterised finite element modelling of RC beam shear failure," in ABAQUS users' conference, vol. 14.

15. A. C. I. C. 440, 1996, "State-of-the-art report on fiber reinforced plastic (FRP) reinforcement for concrete structures,".

16. D. M. Cotsovos, N. D. Stathopoulos, and C. A. Zeris, 2008, "Behavior of RC beams subjected to high rates of concentrated loading," J. Struct. Eng., vol. 134, no. 12, pp. 1839-1851.

17. T. D. Hrynyk and F. J. Vecchio, 2014, "Behavior of Steel Fiber-Reinforced Concrete Slabs under Impact Load.," ACI Struct. J., vol. 111, no. 5.

18. T. D. Hrynyk and F. J. Vecchio, 2014, "Behavior of steel fiber-reinforced concrete slabs under impact load," ACI Struct. J., vol. 111, no. 5, pp. 1213-1224. 